\title{
Review
}

\section{Science and society of knowledge}

by Andrea Cerroni,

Utet, Torino 2007

\section{Pietro Greco}

Probably among the first to deal with it, nearly sixty years ago, Norbert Wiener, the founding father of cybernetics (The human use of human beings. Cybernetics and Society, Houghton Mifflin Company, London, 1950), prefigured its opportunities, as well as its limitations. Today, it is a quite common belief. We have entered (are entering) a new, great era in the history of human society: the age of information and knowledge.

It is an era founded on the never-ending production of new scientific knowledge and on the type of technology that, as stated by the sociologist Luciano Gallino (Tecnologia e democrazia, Einaudi, Torino, 2007), «incorporates endless and ever-growing volumes of scientific knowledge».

Given the importance of the changes linked to this process, the new era of knowledge, founded on a knowledge-pervaded science and technology, develops and outdoes the industrial era, founded on machines, that in its turn had developed and outdone the agricultural era, founded on plant and animal farming.

In this new era, the value of the goods produced by men is less and less defined by manual labour and more and more by the added knowledge rate. This great transition, apparently involving and unifying what Karl Marx named structure and superstructure of society, production and culture, creates high expectations: of economic development (in the year 2000 the European Union set the goal of becoming the leader of the society of knowledge); of human development (more knowledge available means more freedom); and also of sustainable development (we are given the opportunity to increase the wealth of the nations producing immaterial goods, and now with a low environmental impact).

Yet it creates mirror-like fears; of new horrors (development of hugely powerful weapons); of new exploitation forms (the birth of "human slaves", as Wiener defined them); of inequalities between nations and within nations (the cultural divide); of a new unsustainable growth (creation of a wider global middle class, characterised by a consumer lifestyle).

There is a vast literature describing the birth and the problems related to this new phase of the human social and cultural history. Yet only a few have wondered about the answers to some fundamental questions: what actually is this knowledge the human society has started to receive information about? What the role played by science in it all? Is it possible - and how - to build a democratic society of knowledge?

The answers to these questions - in an attempt to fill a gap Italian sociology is particularly affected by - are provided very systematically and clearly by Andrea Cerroni, a sociologist of science and of science communication at the Bicocca University of Milan, in the book Scienza e società della conoscenza, recently published by UTET in Turin.

Andrea Cerroni starts his search for foundations from a distinction which is not obvious at all: the one between information and knowledge. Frequently used as synonyms, they actually are two different things that must be acknowledged as two different things.

Not that the theoretical problems in defining information, raised precisely by Norbert Wiener, have all been solved. However, the concept of information can be associated to discrete and measurable quantities. We talk (and measure) in terms of discrete bits of information. But that does not apply to the concept of knowledge. Nobody has talked seriously about bits of knowledge. This is because knowledge, according to Cerroni, is not «mere information». It cannot be associated to a number. It is not physically measurable. Instead, it is a resource needed to interpret and process information. It is therefore a cultural and social process, rather a complex one. Knowledge, indeed, is explicit and implicit, theoretical and practical, social by its very nature. 
The result in practical terms is that, in the economy of knowledge, the capacity of producing development and of adding value to the goods produced is not determined to a large extent by the transfer of discrete packages of information (for example from universities and research laboratories to enterprises), rather by the construction of an overall environment with indefinite borders, although with a strong innovation culture.

Certainly, knowledge - defined also as a cultural process and not as a «package of information»belongs to the whole human history and characterises it. But then, why are we talking today of a new society of knowledge? Well, firstly because today, in the age of the integration of economies we call globalisation, the «circulation of knowledge» (that we prefer to define as «communication of knowledge», made up predominantly of «science communication», editor's note) is ever more frequently acquiring the feature of universality, that by nature concerns all the individuals on earth. Additionally, because the walls that were separating the world of scientists from the rest of society have come tumbling down. There is more and more science in society and there is more and more society in science - as rightfully considers Cerroni -, in a new global circulation (in a new global communication) that redistributes the roles (without levelling their specific features) of those who produce new knowledge and those who use it (and re-shape it).

Hence, not only do the words by Wiener sound more effective than ever: today «living, to a man, means participating in a large global system of communication». But also, at a close look, circulation (communication) is also the heart of democracy in the society of knowledge.

Even though knowledge in general and science are hardly appropriable (it is difficult to confine them 'in a drawer'), and thus devoid of rivalry (use does not degrade knowledge - on the contrary, it adds value to it, so that the need to own it in an exclusive form does not exist), knowledge is not a natural public property. On the contrary, publicity for this property must be continuously conquered (by politics), both because free circulation increases its value and opportunities, and because this way it should not turn into a (the) new factor of social exclusion, but into a (the) new factor of social inclusion.

Therefore, what is needed is a system for the communication of knowledge, to be "larger and larger", to use Wiener's words. This is because a "large" communication system facilitates everybody's access to science. By democratising it.

Hence, communication is at the heart of the society of knowledge. Because, as Cerroni underlines, it becomes a synonym for innovation. And because it determines its democracy rate. But, on its turn, the communication of knowledge cannot be seen as a «mere transmission of information», but it is a vast cultural and social process. A complex, yet comprehensive growth of society. Only those who take this perspective can aspire to enter the (democratic) society of knowledge. This is why the book on the theory of knowledge by Andrea Cerroni is not only addressed to the specialists, but, in a circular way, to all of us.

It is indeed for not having understood the era we live in, along with its foundations, that many social systems - including the Italian one - find it hard to enter the new economy and the new society of knowledge. And contribute less than others to its democratisation.

Translated by Massimo Caregnato 